\title{
ESTRATÉGIAS INDIVIDUAIS E INSTITUCIONAIS E O AVANÇO DA REFORMA LUTERANA NO NORTE EUROPEU: O CASO DA LIVÔNIA
}

\author{
André Szczawlinska Muceniecks ${ }^{1}$
}

\begin{abstract}
Resumo: Este artigo analisa os processos que conduziram à instituição do Luteranismo na Europa do Norte, em particular na Confederação da Livônia. Apresentaremos de início um panorama da reforma sueca de Gustav Vasa, como evento exemplar de adoção da reforma por um monarca em processo de fortalecimento, seguido por um estudo de caso mais detalhado da Reforma na Livônia, que destoa das linhas gerais estudadas nos movimentos reformadores luteranos e permite a observância de elementos notavelmente populares. For fim, demonstramos a necessidade de se considerar as Reformas religiosas do século XVI como eventos levados a cabo por agentes diversos, motivados por razões igualmente diversas, que vão de motivações espirituais e religiosas às de ordem política e econômica e acabam por convergir em estratégias de benefício mútuo.
\end{abstract}

Palavras-chave: Reforma luterana; Europa setentrional; Suécia; Livônia, Ordem Livoniana.

\section{INDIVIDUAL AND INSTITUTIONAL STRATEGIES AND THE ADVANCEMENT OF THE LUTHERAN REFORM IN NORTHERN EUROPE: THE CASE OF LIVONIA}

Abstract: This article analyses the processes that led to the institution of Lutheranism in Northern Europe, particularly in Confederation of Livonia. Initially we shall present a survey of the Swedish reform of Gustav Vasa as exemplary, in a case of adoption of the Reform by a monarch intending to strenghtening its own monarchy. Following, we will present a case study of Reform in Livonia, which departs from the general lines studied in the Lutheran reform movements and allows to observe religious reforms in XVIs as events led by diverse agents, motivated by equally diverse agendas, from spiritual motivation to political and economic interests. These agents converged with strategies used to mutual benefit.

Keywords: Lutheran reformation; Northern Europe; Sweden; Livonia; Livonian Order.

\section{ESTRATEGIAS INDIVIDUALES E INSTITUCIONALES Y EL AVANCE DE LA REFORMA LUTERANA EN EL NORTE DE EUROPA: EL CASO DE LIVONIA}

Resumen: Este artículo analiza los procesos que condujeron a la institución del Luteranismo en Europa del Norte, en particular en la Confederación de Livonia. Presentaremos de inicio un panorama de la reforma sueca de Gustav Vasa, como evento ejemplar de adopción de la Reforma por un monarca en proceso de fortalecimiento, seguido por un estudio de caso más detallado de la Reforma en Livonia, que destoa de las líneas generales estudiadas en los movimientos reformadores luteranos y permite la observancia de elementos notablemente populares. Para fin, demostramos la necesidad

\footnotetext{
${ }^{1}$ Doutor em História Social pela Universidade de São Paulo. Pós-doutorando na UNICAMP. Professor de História do Cristianismo na Faculdade Teológica Batista de São Paulo. E-mail: muceniecks@yahoo.com
}

Fronteiras: Revista de História | Dourados, MS |v. 19 |n. 34 |p. 71 - 93 | Jul. / Dez. 2017 
de considerar las Reformas religiosas del siglo XVI como eventos llevados a cabo por agentes diversos, motivados por razones igualmente diversas, que van desde motivaciones espirituales y religiosas a las de orden político y económico y acaban por converger en estrategias de desarrollo y beneficio mutuo.

Palabras clave: Reforma luterana; Europa septentrional; Suecia; Livonia, Orden Livoniana.

\section{INTRODUÇÃO}

Nossa intenção nesse artigo é ofertar uma análise de especificidades e diferenças na difusão da Reforma Luterana no norte, especificamente em seus anos iniciais da década de 1520 na Confederação da Livônia, ofertando um breve contraponto da implantação da Reforma no reino da Suécia, outra nação onde o processo de mudança religiosa deu-se também já a partir da mesma década mas em contexto político muito diverso.

Praticamente a totalidade da discussão apresentada aqui é inédita em língua portuguesa com exceção de uma ou outra referência mínima em manuais de História da Igreja (i.e., "História da Igreja na Reforma e na Renascença", de Daniel-Rops), mas também não é de fácil acesso no Ocidente e mundo de língua anglo-saxã. Uma infinidade de obras sobre as Reformas Protestantes ou sobre a Reforma Luterana simplesmente omitem os ocorridos nas áreas onde tal Reforma foi implantada, repetindo-se e se focando apenas nos territórios do Sacro Império Romano Germânico ou no contexto da Europa Ocidental.

Pretendemos, desta forma, se não preencher totalmente uma lacuna séria na discussão das Reformas do século XVI, em momento oportuno no qual a mesma é lembrada, comemorada ou lamentada em diversos locas do mundo, ao menos diminuir o vazio, ao menos ofertar material de referência, ainda que breve. Evidentemente, pelo próprio estado da discussão já apresentado, muito do que será discutido aqui necessita de grande dose de contextualização e de apresentação de certa forma generalista de forma a tornar a leitura acessível.

Parte considerável das informações sobre os reformadores livonianos é discutida apenas nas línguas alemã, letã e estoniana, muitas vezes em obras não digitalizadas ou disponíveis on-line, tornando o acesso à bibliografia tarefa difícil. 
Parte considerável dessa bibliografia se beneficiaria de atualização; é notório, por exemplo, que a obra mais completa sobre a reforma na Livônia, da pena de Arbusow, date ainda de 1920, e as biografias referenciais e discussões sobre os reformadores propriamente ditos seja ainda mais antiga. Os periódicos letões Ceľ̦s ("Caminho") e Mantojums ("Herança”) apresentam por vezes artigos ligados ao tema; destaque, por exemplo, à edição de 1996 de Celšs̆, dedicada à Reforma Luterana no território da atual Letônia.

Por outro lado, obras relativamente mais recentes foram lançadas, como a monumental História da Letônia de Dunsdorfs e Spekke (Latvijas vēsture), publicada em 1964 no seu exílio, e o curso de história da Igreja de Feldmanis (2011); no entanto, se tratam de história de caráter generalista, deixando ainda espaço para a compreensão de muitos aspectos do contexto. Não se pode diminuir o efeito que as décadas de ainda recente domínio soviético imprimiram na academia dos países Bálticos, em particular no campo da História da Igreja e Teologia luteranas, devido às dificuldades colocadas pelo estado nas igrejas; em adição a isso, muito da historiografia relativa ao tema ainda precisa lutar com o status de histórias oficiais e nacionais, quase que positivista, com que muito do tema foi tratado.

Dessa forma, é possível se encontrar na historiografia nacional letã uma tensão e dualidade entre os espectros extremos aos que os nacionais foram lançados, entre a historiografia germânica, tradicional na área, de aspecto fundador mas opressor dos nativos por mais de 700 anos, e o influxo de ideias Marxistas-Leninistas, de duração infinitamente menor, mas que deixaria marcas e ressentimentos ainda maiores na nação como um todo.

Não há espaço aqui para se aprofundar a discussão, mas há de se notar os esforços da academia letã em transpor tais limites e gradativamente abrir-se e comungar com o Ocidente, inserindo obras e autores discutidos no mundo anglo-saxão contemporâneo ao lado das tradicionais obras de autores do mundo germânico, empregando recursos da internet e tomando iniciativas no sentido de promover a cooperação com acadêmicos no estrangeiro; há muito ainda, no entanto, a ser feito nesse sentido.

Há de se salientar que a relevância das Reformas religiosas do século XVI para a historiografia dos países da Europa Setentrional é significativamente maior do que para a historiografia Ibérica ou Mediterrânica, na medida em que as reformas consistem 
em parte dos marcos de transição histórica na região, marcando a passagem do medievo para a modernidade, sejam nos estados monárquicos escandinavos ou nas regiões de composição política mais sui generis como as terras da antiga Ordem Teutônica, secularizadas e, ao mesmo tempo, luteranizadas. O impacto das grandes navegações fezse sentir de forma mais tardia no norte, e o próprio Renascimento esteve ligado diretamente às reformas religiosas (SAWYER; SAWYER, 2003, pp.76-79).

Não se deve, portanto, subestimar o papel das reformas religiosas setentrionais do XVI; mais além: tais reformas devem ser estudadas não apenas enquanto fenômenos de ordem estritamente religiosa, mas de forma mais ampla, incorporando-se questões de ordem política e cultural.

Apresentaremos nesse artigo dois casos distintos de Reforma religiosa ocorridos no âmbito do Norte Europeu; inicialmente, de forma mais breve, os inícios da Reforma Sueca, como exemplo de reforma religiosa ocorrida em uma monarquia em processo de centralização de estado. A seguir nos deteremos de forma mais detalhada e biográfica da reforma luterana ocorrida na Confederação da Livônia e alguns seus agentes principais. Ambos os casos ocorreram já na década de 1520, apresentando, desta forma, material rico para a análise do período inicial de expansão da Reforma Luterana, em dois contextos distintos, particularmente nos âmbitos políticos e sociais.

\section{A REFORMA LUTERANA NA EUROPA SETENTRIONAL: A SUÉCIA DE GUSTAV VASA E O FORTALECIMENTO DAS MONARQUIAS NACIONAIS}

Em termos políticos, a Reforma na Escandinávia coincide com o fim da união de Kalmar, união dinástica das coroas Danesa, Norueguesa e Sueca, iniciado em 1397, e de supremacia Danesa política no Báltico. Na Prússia e na Livônia, áreas controladas pela Ordem Teutônica e por arcebispados locais, o século XVI assistiu à secularização das terras da ordem.

Economicamente, a Reforma Luterana atingiu rapidamente todo o Báltico em grande parte pela prévia hegemonia econômica germânica exercida pela Liga Hanseática. Simultaneamente, no entanto, a preponderância da Hansa nos territórios Escandinavos foi fortemente reduzida no século em questão (OPSAHL, 2013, pp.7390), ao mesmo tempo em que os alemães consolidavam-se como elite detentora de terras e poder político, econômico e religioso na Prússia e particularmente na Livônia. 
$\mathrm{Na}$ Prússia, os antigos prussianos foram completamente assimilados pelos alemães, enquanto que na Livônia e Estônia os nativos foram reduzidos à servidão, dominados pela elite germânica. A Reforma luterana abriria possibilidades e esperanças de alguma mudança de ordem social, mas não tardaria para que as elites germânicas adaptassem-se às novas conjunturas religiosas.

As ideias luteranas chegaram rapidamente nas nações escandinavas, devido à já referida presença de mercadores alemães e cidades ligadas à Hansa. A Suécia foi o primeiro reino a adotar o luteranismo, rompendo com Roma na primeira metade da década de 1520, em um processo amplo, de implicações e disputas não apenas no campo religioso, que se completou com o fortalecimento do rei Gustav Vasa (ou: Gustav Eriksson, 1495-1560), o rompimento da Suécia com a União de Kalmar e o Concílio de Örebro, ocorrido em 1529. Na Dinamarca a prática do luteranismo foi permitida a partir de 1527, por ocasião da Dieta de Odensee, e até 1535 definiram-se práticas litúrgicas e doutrinas básicas, em um processo que teve seu ápice em 1535, com o luteranismo decretado religião estatal pelo rei Kristian III (DANIEL-ROPS, 1996, pp.428-430). No momento a Noruega encontrava-se sob a coroa Dinamarquesa.

A Reforma Luterana na Suécia marcou duas rupturas significativas, a nível religioso e político, processos que, apesar de suas especificidades constituintes, não podem ser dissociados entre si. Em adição às transformações específicas no campo religioso, a dinâmica política própria dos finais do medievo sueco, de inserção na União de Kalmar, submissão aos reis daneses e sujeição parcial ao papado, deu lugar ao governo de monarcas empenhados no fortalecimento do poder régio, procurando para tanto suprimir outras fontes de resistência.

Como já afirmado, a despeito da facilitação da implantação das ideias luteranas pela forte presença germânica nas cidades Escandinavas, o século XVI foi marcado pela diminuição da influência alemã no comércio e economia sueco e danês, concomitante com o fortalecimento de suas monarquias nacionais.

O caso sueco foi precoce, tanto no sentido da emancipação política quanto da adoção oficial de medidas reformadoras. Gustav Vasa, ou Gustav I, eleito rei em 1523 e morto em 1560, liderou os suecos contra o rei Kristian II (1481-1559), da Dinamarca. Gustav aproveitou-se do forte sentimento nacional anti-danês a fim de fortalecer sua reivindicação ao trono. 
O rei Kristian II, da Dinamarca, executou em 1520 na cidade de Stockholm 82 indivíduos da nobreza e do clero sueco, partidários dos Sture, que defendiam o rompimento da Suécia com a união de Kalmar. A execução, ocorrida em 10 de novembro de 1520 , deu-se menos de uma semana após a consagração do arcebispo Gustav Trolle (1488-1535), apoiador da união e de Kristian, que ocorrera no dia 4. O arcebispo recém-nomeado acusou os adversários de heréticos (WOLKE, 2006, p. 141).

O caso veio a ser conhecido como "Banho de sangue de Stockholm", e tornouse um dos mitos fundadores da historiografia sueca moderna, bem como ponto de contenda entre as historiografias escandinavas. O fato é que o ocorrido foi, se não instrumentalizado, ao menos usado ideologicamente por Vasa ao liderar os suecos contra os daneses (JOHANNESSON, 1991, pp.14ss).

Parte das medidas tomadas no processo de fortalecimento de seu poder régio incluíram o rompimento com o papado, que apoiava Gustav Trolle, a estatização e, em alguns casos, redistribuição das propriedades eclesiásticas. Trolle foi exilado por Vasa e substituído por Johannes Magnus (sueco: Johan Månsson, 1488-1544) em 1524, visto no momento como partidário de Vasa, movimento que não foi apoiado pelo papa Clemente VII.

Johannes, no entanto, era fiel a Roma e sua doutrina, e via com preocupação crescente as simpatias e benesses de Vasa aos luteranos; se concordava com a independência sueca em relação aos daneses e Kalmar, não podia endossar a forma como Vasa estava a atingir tal objetivo, logo se tornando um impedimento às medidas de Vasa.

Dentre os luteranos se destacam nesse período inicial os irmãos Laurentius (sueco: Lars Persson, 1499-1573) e Olaus Petri (sueco: Olof Persson, 1493-1552), que por toda a década de 1520 batalhavam pela divulgação de ideias reformadoras na Suécia. Olaus Petri - que estudara na própria Wittenberg em 1518 - casou-se em 1525, e os irmãos publicaram uma tradução do Novo Testamento para o sueco em 1526, ano no qual Johannes foi enviado por Vasa para a Rússia como embaixador; a tradução completa da Bíblia para o sueco seria publicada em 1541, vindo a ser conhecida como "Bíblia de Vasa".

Por fim, após o Concílio de Orebro, ocorrido em 1529, Johannes Magnus partiu em definitivo para o exílio, com seu irmão Olaus Magnus (sueco: Olof Månsson, 1490-1557). Em 1530 suas posses na Suécia foram confiscadas e suas rendas cessaram. 
Os irmãos passariam o restante de suas vidas na Polônia e Itália, mudando-se de Dantzig para Roma em 1537.

Na Suécia, Laurentius Petri recebeu do rei a posição de arcebispo em 1531; Roma demorou a tomar posição, inicialmente insistindo na consideração de Gustav Trolle como arcebispo. Apenas em 1533, após viagem de Olaus Magnus para Roma, Johannes foi reconhecido arcebispo por Roma, posição no momento apenas pro-forma e passada após sua morte, em 1544, para Olaus Magnus. A insistência romana na manutenção de Trolle e sua demora em atender às reivindicações dos irmãos Magnus apenas facilitaram o processo de fortalecimento das ideias luteranas em território sueco, a um ponto que em menos de duas décadas as transformações eram irreversíveis.

\section{REFORMA LUTERANA NA CONFEDERAÇÃO DA LIVÔNIA}

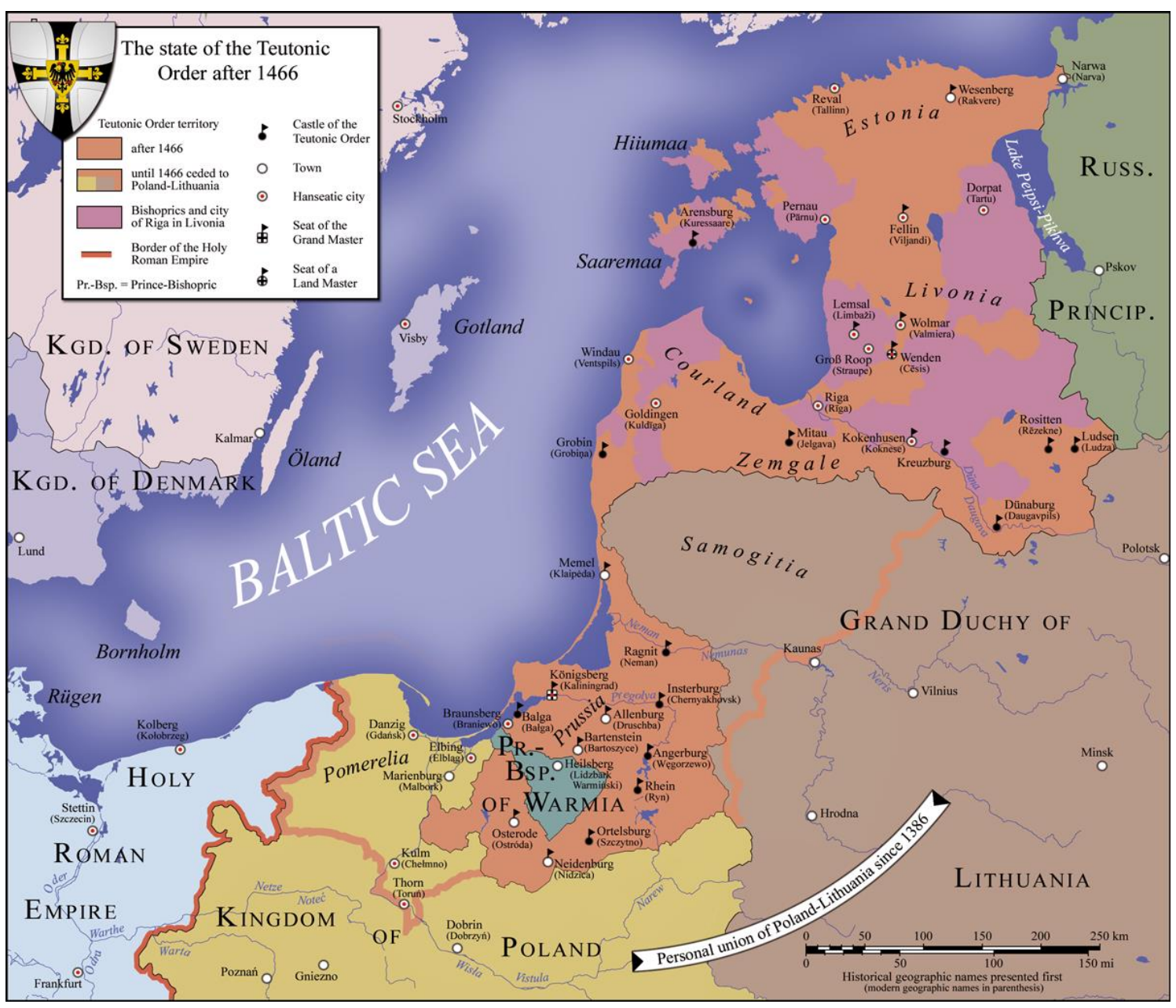

Os estados teutônicos e a Confederação da Livônia após 1466. Fonte: Bollman, S. Obtido em: <https://upload.wikimedia.org/wikipedia/commons/b/b2/Teutonic_Order_1466.png> Uso permitido sob a "GNU Free Documentation License". 
Processos diferentes se deram na Prússia e na Livônia, anteriormente territórios pertencentes em parte à Ordem Teutônica. Na segunda metade do século XV a Ordem dividia-se em três regiões, consistindo de propriedades no Império, na Prússia e na Livônia. No caso prussiano, os territórios da Ordem foram secularizados em 1525. O responsável pelo processo foi o então grão-mestre, Albrecht (1490-1568), que tornou o antigo território monástico da Ordem em território Prussiano em um grão-ducado hereditário vassalo do rei da Polônia, por meio do tratado da Cracóvia, assinado em 1525 (URBAN, 2003, pp. 256-59).

No século XVI a Ordem Teutônica encontrava-se em longo processo de declínio, iniciado pelo menos desde 1410, ocasião de grande derrota sofrida diante da Polônia e da Lituânia na Batalha de Grunwald.

Albrecht provavelmente foi convertido ao Luteranismo por influência de Andreas Osiander (1498-1552) em 1522, ocasião na qual o grão-mestre participara da Dieta de Nuremberg, em uma tentativa vã de obtenção de recursos da parte do Sacro Império Romano Germânico. Dirigindo-se posteriormente para Wittenberg seria aconselhado pelo próprio Lutero a abandonar as regras de sua ordem, tornar seu território em sua possessão hereditária e se casar. Albrecht já aceitara a posição de grãomestre da Ordem com ressalvas, em particular a necessidade de se tomar votos monásticos e celibatários. É certo que as recomendações de Lutero encontraram nele terreno fértil, mas não devemos subestimar as razões de ordem mais propriamente espiritual (URBAN, 2003, pp. 254s).

Por fim, Albrecht tornou-se vassalo de seu tio Sigismund I, rei da Polônia. As propriedades da Ordem e da Igreja Romana foram confiscadas e parcialmente redistribuídas entre a nobreza, que jurou aliança ao novo duque. Os nativos da região, antigo-prussianos linguisticamente aparentados às tribos lituanas e letãs ao norte, foram germanizados e completamente assimilados ao longo dos séculos.

É o caso da Ordem na Livônia que nos interessa mais de perto; a área apresenta desenvolvimentos únicos, que merecem análise em especial. $\mathrm{Na}$ região, a Ordem Teutônica não se constituía a única instituição de poder, antes dividia o controle da área com a Confederação da Livônia (URBAN, 2003, p. 259).

A Confederação da Livônia surgiu após uma série de guerras civis ocorridas entre 1296-1330, 1313/1330, e 1343-1345. Após a última, uma revolta entre os estonianos ocasionou a anexação da Estônia danesa pela Ordem Teutônica na Livônia 
em 1346, ocasião na qual os vassalos alemães venceram os daneses após conterem a revolta nativa.

O equilíbrio de poder na região era delicado; a paz obtida com os poderes externos no início do século XVI não se refletia internamente (URBAN, 2003, p. 259). Em teoria o arcebispo de Rīga detinha a autoridade máxima, tanto enquanto senhor feudal como autoridade eclesiástica sobre a Ordem Teutônica, que passaria a ser conhecida na Livônia como Ordem Livoniana. Os cavaleiros, no entanto, não se sujeitavam facilmente ao poder episcopal, e a Ordem Livoniana tentaria unificar seus territórios sob o domínio do arcebispo; destarte, o grão-mestre da Ordem detinha autoridade independente do arcebispo em seus territórios. No campo da própria igreja havia fatores que comprometiam a ação de uma autoridade central; de menor relevância eram os bispos locais de Dorpat ${ }^{2}$, da Kurland e de Ösel-Wiek. Por fim, havia um grande número de cidades ligadas a Liga Hanseática, empenhadas na manutenção de suas próprias liberdades e pregorrativas específicas.

Em 1418-19 fundou-se a Confederação da Livônia, por iniciativa de Johannes Ambundii, nomeado arcebispo de Rīga pelo papa Martinho V em 1418. Uma união marcada por conflitos e disputas de poder entre a Ordem Livoniana, a igreja representada pelos bispos - e as cidades ligadas à Liga hanseática. O arcebispo Ambundii reuniu um Landtag em Walk ${ }^{3}$ em 1419 a fim de pacificar os vários poderes nos territórios da Livônia. Na dieta participaram membros da Ordem Livoniana, bispos, vassalos e representantes das cidades (MUTHER, 1875, p.25).

Em 1435 a Ordem Livoniana foi derrotada na batalha de Swienta/Pabaiskas e seu grão-mestre, bem como muitos cavaleiros de alto-escalão, morreram. Os cavaleiros da Livônia lutaram ao lado de Svitrigaila, que travava lutas dinásticas contra Sigismund Kestutaitis, na guerra civil lituana (1432-38).

Com a derrota, a ordem teve de estreitar seus laços com seus vizinhos da Livônia. Em 1435 foi assinado um tratado em Walk pelo arcebispo de Rīga, os bispos da Curlândia, Dorpat, Ösel-Wiek e Reval $^{4}$, representantes e vassalos da Ordem Livoniana, enviados de Rīga, conciliares municipais de Reval e Dorpat.

\footnotetext{
2 Atual Tartu, na Estônia. No caso de nomes diferentes, Serão empregados aqui os nomes das cidades conforme uso do século XVI, usualmente os nomes germânicos, com a indicação dos nomes equivalentes atuais.

${ }^{3}$ Atual Valga, na Estônia.

${ }^{4}$ Atual Tallinn, capital da Estônia.
}

Fronteiras: Revista de História | Dourados, MS |v. 19 | n. 34 | p. 71 - 93 | Jul. / Dez. 2017 
A confederação deixaria de existir enquanto entidade política autônoma na segunda metade do século XVI. Um a um os estados formadores da Confederação da Livônia deixaram de existir durante a guerra da Livônia, que ocorreu entre 1558-1582, quando seus territórios foram divididos entre Dinamarca, Suécia e Polônia-Lituânia. A Reforma religiosa terá papel preponderante na transformação das dinâmicas de poder na Livônia.

Como apontado por Packull (1985, p. 343), os reformadores na Livônia foram analisados por Joachim Kuhles num viés explicativo de luta de classes; Andreas Knopken, o pioneiro, foi visto como representante dos interesses das classes média e alta; Sylvester Tegetmeyer, dos pequenos burgueses, enquanto Melchior Hoffman, mais conhecido por seus envolvimentos posteriores com os Anabatistas na Região dos Países Baixos, defenderia interesses revolucionários e mesmo uma aliança entre plebeus e camponeses nativos. A reação católica, emblemática em figuras como Johann Blankenfeld, arcebispo de Rīga, e Laurentz Lang, representariam os interesses reacionários feudais. Com frequência, ressalta-se um caráter supostamente "plebeu", "popular", ao menos dos primeiros momentos de reforma na Livônia (DRUVIN̦A, 1996, p. 24; PLACKULL, 1996[1985], p. 27).

Quando, apenas em 1559 o então grão-mestre da Ordem Livoniana Gotthard Ketler (1517-1587), adotaria o Luteranismo como fé oficial dos territórios da Ordem, a reforma já era majoritária em praticamente todas as cidades da Livônia e Estônia, circunstância propiciada não apenas pela tolerância do grão-mestre Wolter von Plettenberg (1450-1535) na década de 1520, mas pela grande disseminação da mesma em todos os extratos sociais, em grande parte pelo trabalho dos reformadores frente às variadas camadas da população, de nobres a citadinos e plebeus.

Veremos a seguir, de forma fortemente biográfica, um pouco da atuação desses primeiros reformadores; focaremos na obra realizada primariamente a partir de Rīga, pois a partir dessa cidade que a Reforma se espalhou não apenas por toda a Livônia, mas também pela Estônia (LAANTEE 1953, 272).

\section{ANDREAS KNOPKEN: O REFORMADOR “OFICIAL”}

A Knopken atribui-se o papel de reformador principal na Livônia, que foi balanceado mais recentemente em detrimento de uma maior atuação de Tegetmeyer. 
Tanto Knopken quanto Hoffman deixaram uma quantidade relativamente grande de escritos; de Tegetmeyer, no entanto, tem-se apenas fragmentos de seu diário pessoal, em adição a relatos de outras penas, o que contribuiu também para o menor papel a ele atribuído pelas historiografias posteriores, majoritariamente alemã e letã.

Andreas Knopken (c. 1468-1539) é considerado pela historiografia oficial o primeiro reformador da Livônia (FELDMANIS, 2011, pp.104s). Nascido ca. 1468 perto de Küstrin (atual Kostrzyn, Polônia), foi educado em Frankfurt und der Oder (atual Trzebiatow, Polônia). Dirigiu juntamente com Bugenhagen ${ }^{5}$ uma escola em Treptow, na Pomerania, que recebia também alunos vindos de Rīga. Erasmus von ManteuffelArnhausen (ca. 1475/1480-1544), bispo de Cammin opôs-se a ele em 1520, em virtude de sua defesa da doutrina de Lutero; no ano de 1521, Knopken mudou-se para Rīga, onde estava seu irmão Jacob.

Rīga possuía um contexto propício à pregação luterana; ali, já se havia levantado a necessidade de reformas na Igreja, e devido aos laços estreitos na Confederação Livoniana com as cidades do Norte da Alemanha e a Liga Hanseática os escritos de Lutero eram já bastante conhecidos nas margens orientais do Báltico. O arcebispo se encontraria constantemente em oposição aos citadinos, particularmente aqueles ligados com a Liga Hanseática. Os alemães constituíam por volta de $50 \%$ da população das cidades hanseáticas como Rīga e Dorpat, estando em sua maioria ligados à liga (PLACKULL, 1985, p.346), e dessa forma é claro que a situação geral era favorável à medidas reformadas, mas encontrava oposição da autoridade do arcebispo, que supostamente obtinha precedência sobre a Ordem, mas que na prática encontrava-se bastante minada.

Em Rīga Knopken conseguiu a proteção de patronos influentes como o secretário do concílio Lohmüller e o prefeito Durkop. Sob a proteção do último, Knopken realizou uma disputa pública e apresentou uma série de 24 teses discutindo ensinos da Igreja Romana na St. Petrikirche ${ }^{6}$, em 12 de junho de 1522, pregando ali sobre o mesmo assunto em 23 de outubro do mesmo ano. Sua mensagem encontrou acolhida dos citadinos em Rīga, a despeito da oposição do arcebispado, ecoando também nas cidades estonianas (FELDMANIS, 2010, pp. 104ss; LAANTEE 1953, 272).

\footnotetext{
${ }^{5}$ Johannes Bugenhagen (1485-1558) foi nome fundamental na expansão das ideias de Lutero para o leste e norte.

${ }^{6}$ Atualmente, Svētā Pètera baznīca, em letão ("Igreja de São Pedro").
} 
Knopken é descrito como calmo e moderado e, a despeito de decididamente opositor da teologia e doutrinas romanas, evitava confrontos e ataques agressivos; alguns biógrafos chegam a chamá-lo de "leniente" (HAUSMANN, 1882, p.324).

A situação muda com a chegada de Tegetmeyer, vindo de Rostock em 1522. Pregador apaixonado e inflamado, Tegetmeyer atingia e movia as massas, e iniciou-se em Rīga um verdadeiro movimento iconoclasta. A St. Jakobskirche $e^{7}$ foi saqueada e clérigos expulsos; nem mesmo mandatos imperiais foram capazes de restaurar as condições anteriores, e a cidade permaneceu fortemente protestante.

O nome de Knopken não foi associado a esses movimentos violentos, diferentemente de Tegetmeyer, e os dois não tardariam a discordar entre si, havendo a necessidade de haverem definições conciliares em 1532 acerca das devidas atribuições de ambos.

Knopken estava diretamente ligado aos reformadores de Wittenberg, principalmente Melanchton, bem como com Bugenhagen. O próprio Lutero enviaria saudações a Knopken, reconhecendo seu comprometimento com a "verdadeira fé". Escritos de sua lavra seriam publicados em Wittenberg em 1524 e em Rostock, em 1530, sendo amplamente difundidos.

Knopken seria amplamente reconhecido por toda a Livônia; por ocasião da escrita da primeira confissão da Livônia em 1539 por representativos de Rīga, Reval, Dorpat e Wenden ${ }^{8}$, ano no qual Knopken se aposentaria.

Seus passos seriam seguidos por seu filho Matthias, que estudaria em Wittemberg, retornaria para Rīga em 1553 e assumiria o pastorado na St. Petrikirche em 1581.

Mas retornemos ao já mencionado Tegetmeyer.

\section{SYLVESTER TEGETMEYER: O REFORMADOR EXALTADO, MAS ESQUECIDO}

Sylvester Tegetmeyer (Hamburg, ? - 1552, Rīga; letão: Silvestrs Tegetmeijers) é o segundo nome usualmente referido como "Reformador da Livônia". Seu papel na Reforma Livoniana é de certa forma obscurecido pela atuação de Knopken. As informações sobre sua vida não são tão detalhadas quanto se gostaria, e são repetidas na

\footnotetext{
${ }^{7}$ Atualmente, Svètā Jèkaba katedrāle, em letão ("Catedral de São Tiago").

${ }^{8}$ Atual Cēsis, Letônia.

Fronteiras: Revista de História | Dourados, MS |v. 19 | n. 34 | p. 71 - 93 | Jul. / Dez. 2017
} 
maioria dos autores, estando bem resumidas em Böthführ (1894), Arbusow (1921), e Plackull (1985, 1996[1985]). Com exceção do último, que publicou um breve estudo sobre os fragmentos do diário de Tegetmeyer no Jounal of Baltic Studies, uma visão comumente compartilhada na historiografia luterana é a de que, diferentemente de Knopken, Tegetmeyer seria um indivíduo impetuoso, impulsivo, dirigido por sede de poder, além de excêntrico e fanático (PLACKULL, 1985: p. 343).

Tegetmeyer nasceu em Hamburg, provavelmente por volta de 1495. Iniciou seus estudos na Universidade de Rostock em 1511, mas não se graduou em 1515 como esperado, ou ao menos não se tem o registro do ocorrido. Provavelmente esteve por algum tempo em Leipzig, tendo retornando depois para Rostock, onde receberia o grau de mestre (magister) em 1519, sendo que no mesmo ano assumiria a posição de Disputator na residência estudantil do "leão vermelho", que incluía organização e supervisão de debates (PLACKULL, 1985, p. 344).

Em 1520 assumiria o papel de capelão na catedral de S. Tiago (alemão: St. Jakobkirche), em Rostock, talvez por influência de sua boa relação com Barthold Moller (ca. 1460-1530), seu antigo professor. A essa altura, Tegetmeyer ainda mostrava-se leal à igreja romana.

É entre 1520 e 1521 que acontece sua ruptura com Roma, mas não se conhecem as formas exatas de como isso aconteceu; Plackull (1985, p. 344), baseandose em Arbusow (1921), sugere razões que vão desde seus estudos humanísticos, evidenciados pelo conhecimento de ao menos três línguas, até discordância com seus antigos professores; quiçá Tegetmeyer passara por influências de Valdenses e Hussitas.

Seus contatos com as ideias de Martinho Lutero em Wittenberg datam de 1521, ano no qual seu nome encontra-se listado na universidade; no ano em questão Karlstadt promovia ideias ainda mais radicais que as do próprio Lutero, então em exílio em Wartburg, e eclodiam as ideias do grupo que viria a ser conhecido como "Profetas de Zwickau". O retorno de Lutero pacificaria a situação em Wittenberg; é possível que Tegetmeyer tenha sido influenciado por Karlstadt nessa ocasião, como presume Plackull (1985, p.347), ou que, como considera Arbusow (1921: p. 238), seu próprio "radicalismo evangélico" (evangelischem Radikalismus) seja um pouco posterior; há consenso, no entanto, acerca das influências das ideias de Karlstadt.

No ano seguinte (1522), Tegetmeyer se mudaria para Rīga, onde seu irmão morrera sem deixar herdeiros, e se tornaria clérigo na St. Jakobkirche. Próximo ao final 
desse ano sabe-se que Tegetmeyer já travara amizade com Johannes Lohmüller, secretário municipal, e com Melchior Hoffman. Consta que Lohmüller chegara a trocar correspondência com Lutero em 1523, referente aos frutos da Reforma no Norte e pedindo orientação sobre como prosseguir (GRUDULIS, 1998, p.129).

Os magistrados de Rīga apoiaram as reivindicações dos citadinos, e tomaram o lado dos reformadores; enquanto Knopken tornava-se o principal pregador na catedral de St. Petrikirche, Tegetmeyer faria o mesmo em St. Jakobkirche.

A Chronicon Saxoniae de Chytraeus relata que Tegetmeyer pregaria ardorosamente contra o uso de ídolos e imagens e geraria tumulto e iconoclastia em Rīga por volta de 1524, posição citada sem maiores reflexões por Plackull (1985, p. 347), mas questionada anteriormente por Böthführ (1894, p. 529), devido aos desenvolvimentos subsequentes da carreira de Tegetmeyer e o convite de Dorpat feito ao mesmo. Aparentemente a pregação do reformador dirigira-se primordialmente contra os franciscanos de Rīga, em particular Antonius Bomhower, que com a conivência do arcebispo de Rīga viajaria para Roma a fim de conseguir um interdito papal contra a cidade.

A pregação de Tegetmeyer encontraria, dessa forma, grande suporte principalmente da Liga dos cabeças negras, guilda de mercadores solteiros de Rīga. O fato é que em 16 de março de 1524 ocorreu manifestação na cidade de Rīga, culminando com a destruição de estátuas e imagens nas principais catedrais da cidade, St. Petrikirche e St. Jakobkirche.

Tegetmeyer rebeceria convite de Dorpat para organizar a igreja local após distúrbios gerados pela pregação de Hoffman. A compreensão dos acontecimentos é difícil; se seu nome fosse considerado como relacionado aos movimentos iconoclastas, dificilmente outra paróquia solicitaria sua ajuda para se organizar após distúrbios da mesma natureza. O reformador, no entanto, se dirigiria para a cidade, onde ainda cooperaria com Melchior Hoffman.

A maior parte das entradas do diário de Tegetmeyer datam de 1525; em sua grande maioria, são referências indicando locais e datas onde seu autor pregou; em alguns casos, como na entrada de 28 de fevereiro de 1525, tem-se o registro do texto bíblico usado, com o adendo que foi lido em latim, ou então a entrada de 02 de Julho do mesmo ano, quando ele afirma não lhe ter permitido conduzir a missa em alemão. 
Poucas entradas são de maior relevância. Uma única entrada se refere a Hoffman; a primeira do ano de 1525, afirma que

[...] o bailio do bispo em Dorpat tentou prender Melchior Hoffman, um peleiro, porque ele pregou o evangelho. Depois disso, os cidadãos e jovens jornaleiros começaram a resistir ao bailio, e quatro que estavam do lado dos citadinos foram mortos, dois alemães e dois nãoalemães. O bailio fugiu para o palácio (castelo). Então a comunidade inteira se reuniu e invadiu todas as igrejas, e quebrou todas as imagens e painéis na St. Petrikirche, e queimou os painéis e derrubou ou quebrou todas as taças [...] (TEGETMEYER, Diário).

Parece que é nesse período que data o rompimento entre os dois; ainda que os dois tivessem ideias muito semelhantes, a pregação de Hoffman resultaria em sua prisão, o que incitaria uma manifestação na qual 4 pessoas morreriam, cerca de 20 seriam feridas, bem como culminaria com ataques a igrejas e capelas. Tegetmeyer não demonstra críticas a Hoffman no que se possui do seu diário, como evidenciado pelo trecho citado, mas posteriormente parece ter responsabilizado a Hoffman pelo ocorrido.

Tegetmeyer pregaria diariamente por quatro semanas seguidas na cidade de Tartu e sua eloquência e oratória seriam conhecidos em outros locais. Finalmente, por tal razão, em 1525, o religioso se mudaria para Wolmar ${ }^{9}$, onde se casaria anos mais tarde. No mesmo ano as cidades de Rīga, Reval e Dorpat exigiram liberdade religiosa e o fim do domínio secular da parte dos bispos romanos. A circunstância permitiria que Tegetmeyer retomasse sua pregação de forma ardorosa, algo que deixara de fazer parcialmente devido às restrições dos bispos de Dorpat. Parece que por sua intransigência, no entanto, esforços da parte dos reformadores de convencer a nobreza alemã a apoiar a reforma e adotar postura aberta contra o arcebispado e as ordens monásticas foram comprometidos (PLACKULL, 1985, p. 347).

Finalmente, em 1526 as cidades de Rīga, Reval e Dorpat promoveram um sistema uniforme para a igreja da Livônia, encarregando Tegetmeyer de sua escrita; a essa altura, o ímpeto inicial da reforma, grandemente ligado à figuras de pregadores populares como Tegetmeyer e Hoffman, mudaria; as autoridades citadinas passaram a tolerar cada vez menos pregações radicais e, principalmente, manifestações e desordem que derivassem das mesmas (PLACKULL, 1985, p. 349).

\footnotetext{
${ }^{9}$ Atual Valmiera, Letônia.

Fronteiras: Revista de História | Dourados, MS |v. 19 | n. 34 |p. 71 - 93 | Jul. / Dez. 2017
} 
Tegetmeyer permaneceria em Wolmar por muitos anos, mas sua reputação em muitas cidades da Livônia ficaria abalada em razão de seu radicalismo. Em Rīga, no entanto, o pregador manteria laços de amizade e o suporte da Liga dos cabeças-negras e com o partido reformador; em 1528 ele inclusive se casaria com a filha de um mercador da cidade.

Problemas com Knopken ocorreriam em 1532, quando Tegetmeyer exigiu para si o papel de supervisor geral da igreja em Rīga, função que então era exercida por Knopken, cuja atuação Tegetmeyer via como moderada em demasia. Os magistrados da cidade arbitrariam a disputa, e instituiriam um sistema de revezamento entre os dois na posição. Por fim, Tegetmeyer seria apontado como pastor da St. Petrikirche de Rīga, em 1542, a mais elevada posição na hierarquia espiritual da cidade, que manteria até sua morte em 1552.

\section{MELCHIOR HOFFMAN (1495-1533): O REFORMADOR RADICAL}

O terceiro reformador ao qual devemos voltar nossa atenção é Melchior Hoffman. Ainda que haja uma quantidade vasta de bibliografia sobre sua atuação na Europa Ocidental, particularmente no episódio Anabatista de Münster, sua relevância para a reforma na Livônia é raramente estudada, ou mesmo mencionada. A própria historiografia luterana letã procura diminuir e denegrir seu papel na Reforma livoniana; Feldmanis (2011, cap. 6; pp. 104-120) fala sobre "rebeldes, loucos e extremistas" ("atkalkristītājiem, jūsmoṇiem un ekstrēmistiem") no Império, e a eles associa Hoffman, enfatizando não ter havido influência duradoura do mesmo em detrimento do papel de Knopken e Tegetmeyer.

Pode-se dividir a vida de Hoffman em três períodos distintos: o período na Livônia e Báltico, o período como pregador em Schleswig-Holstein e, finalmente, seus anos finais em Strassburg. É notório que em seu período no Báltico, ainda que o tom apocalíptico de sua pregação já estivesse presente, Hoffman ainda apresenta-se como discípulo de Lutero (PETERSEN, 1993, p.88).

As atividades de Hoffman foram registradas na Livônia apenas em 1533, sete anos após sua saída de lá, por ocasião de um landtag ocorrido em Wolmar. Na ocasião, representativos de Rīga, Reval e Dorpat cotejaram ocorridos no passado não tão distante 
a fim de tratar problemas enfrentados no ano em questão, envolvendo um pregador popular de nome Jonas e o secretário da cidade, Hermann Sasse, que o defenderia.

Hoffman vinha da Schwábia, onde nascera por volta de 1495; esteve em Rostock onde deve ter conhecido ou se familiarizado com o trabalho de Tegetmeyer e outros reformadores, e trabalharia como peleiro na Livônia. Sua chegada em Rīga ocorreu em data incerta, mas através de seus escritos e dos fragmentos do diário de Tegetmeyer, pode-se presumir que esteve na cidade por volta de dois anos nas proximidades de 1521, nos quais travou amizade com Tegetmeyer e possivelmente obteve conhecimento de algum idioma local, livônio ou letão. Não permaneceria muito tempo ali e, por razões desconhecidas, teve discordâncias com Tegetmeyer.

Após breve período em Wolmar (1523), Hoffman chegou a Dorpat, em 1524, cidade que permanecia sob controle da Ordem Teutônica e do arcebispado. Ali passou a pregar, atacando a confissão auricular e o uso de imagens.

Defendia a confissão pública no culto, feita de forma geral, congregacional; foi-lhe respondido que o médico precisava, a fim de receitar o remédio certo, ter mais ferramentas para um preciso diagnóstico. O cerne da questão, em termos teológicos, remetia à submissão da fé salvífica à confissão auricular e à absolvição do sacerdote; Hoffman defendia, portanto, a concepção, cara para Lutero, da justificação pela fé. As repercussões de sua mensagem, no entanto, atingiam a própria autoridade clerical, que não desejava abrir mão de mecanismos de controle social.

Após repercussões da pregação de Hoffman em movimentos iconoclastas locais, o concílio da cidade exigiu em 1525 que ele obtivesse testemunho referente á autenticidade de seus ensinos do próprio Lutero, em Wittenberg. Provido de recomendações de Knopken e Tegetmeyer, Hoffman não tardou a partir em viagem para Wittenberg, onde aparentemente conseguiu convencer a Lutero e Johannes Bugenhagen, que enviaram cartas de recomendação para Dorpat (PETERSEN, 1993, p.89).

Em seu retorno, quando viu que a riqueza retirada da igreja não havia sido redistribuída em benefício dos pobres como chegara a ocorrer em Rīga, mas tinha virado ornamentos da esposa e filha do burgomestre, Hoffman pregou ironicamente para que se ajoelhassem diante da santidade, após o que não tardaria para que se tornasse persona non grata na cidade. Provavelmente o burgomestre em questão era Laurentz Lang, que remeteria ao caso de Hoffman quando julgaria posteriormente caso similar num Landtag de 1533 (PACKULL, 1996[1985], pp.37s). 
Salienta-se, no entanto, que em seu retorno a Dorpat, do que se depreende de seus escritos, Hoffman compartilhava da visão de Lutero referente à concórdia entre os diversos estratos sociais; no exato ano de sua viagem para Wittenberg haviam eclodido as guerras camponesas lideradas por Thomas Muntzer e Florian Geyer, e Hoffman ficara impressionado pelo desenrolar dos eventos. Hoffman defendia que não se pegasse em armas a fim de derribar as autoridades instituídas, mas criticava o que via como retrocesso; já fora da Livônia, Hoffman criticaria a circunstância de que os momentos iniciais da Reforma, de quebra das estruturas anteriores de poder, particularmente da hierarquia clerical, pareciam regredir, à medida que se criava uma nova organização eclesiástica, igualmente burocratizada e que continuava a exploração dos menos favorecidos (PLACKULL, 1996[1985], p.42). O teor geral de sua pregação acabava por estimular a revolta das massas mais humildes; para essas, a sublevação contra a opressão e a injustiça apresentava-se como o resultado lógico das mensagens ouvidas.

Não é de se surpreender que Hoffman foi convidado a se retirar da cidade. Partiu para Reval, onde situação similar ocorreria até que, por fim, chegou em Stockholm em 1526. Ali Hoffman foi recebido pela igreja luterana alemã, que lhe ofereceu o ofício de pregador, e chegou a se casar e ter um filho. Hoffman, porém se envolveria com distúrbios devido à sua pregação impetuosa, e não tardaria para que o rei Gustav Vasa solicitasse sua resignação, temendo que o pregador lhe causasse maiores embaraços. A situação levou Hoffman a deixar a cidade. É desses anos que se têm uma das cartas gerais de Hoffman, dirigida aos irmãos na Livônia, bem como três livretos que incluem uma exposição de Daniel capítulo 12, de cunho apocalíptico.

Os anos seguintes são um momento diverso na carreira de Hoffman, de transição. Depois de um pequeno tempo em Lübeck, foi para a Dinamarca, onde obteve favor do rei Frederick I. O rei enviou-o para pregar em Kiel, onde provavelmente tornou-se o primeiro impressor. Sempre pregava e denunciava os abusos locais, e parece ter adotado uma visão da ceia próxima da de Zwinglio. Apenas então dar-se-ia a ruptura com Lutero. Em um colóquio de pregadores em Flensburg, ocorrido em 8 de abril de 1529, Hoffman e João Campanus mantiveram contra Lutero a posição zwingliana da eucaristia; Hoffman recusou o que chamara anteriormente de "mágica" na interpretação luterana, não quis se retratar e foi banido (DEPPERMANN, 1987 [1979], pp. 126s;160).

Finalmente, Hoffman foi para Strassburg, onde se envolveu com os anabatistas locais, sendo rebatizado em 23 de abril de 1530 (ESTEP, 1975[1963], p.109). Hoffman 
manteria sua visão de obediência às autoridades, a despeito do concílio da cidade de Strassburg ordenar sua prisão (WILLIAMS, 1992, p. 393).

Os acontecimentos posteriores são mais amplamente conhecidos pela bibliografia das Reformas, particularmente da obra de autores estudiosos da Reforma Radical como George Williams e William Estep. Dois meses depois Hoffman viajou para a cidade de Emden na Frísia, onde as autoridades permitiram que usasse um dos templos da cidade. Ali ele batizou cerca de 300 pessoas, o que chamou a atenção do clero e ocasionou sua saída da cidade.

Nos três anos seguintes Hoffman viajou entre cidades da Holanda e do norte do Império, até que se tornou convencido em 1533 do final dos tempos após um ancião da Frísia profetizar o retorno de Cristo, que se daria após seis meses de prisão para Hoffman, que exerceria o papel da Elias como testemunha.

Hoffman retornaria então para Strassburg, reunindo-se com sua família; estava certo que a cidade seria o local para o retorno de Cristo na terra, e por instigação própria conseguiu ser aprisionado pelas autoridades.

Nesse ano e no seguinte, no entanto, eclodiu uma rebelião na cidade de Münster. Jan van Matthijs e Van van Leiden alegaram que Hoffman havia errado lugar e tempo do retorno de Cristo; o local correto seria a cidade de Münster. A influência de Hoffman no ocorrido foi indireta;, e a rebelião, que começaria e terminaria de forma sangrenta, contradizia frontalmente sua pregação pacifista.

O sínodo de Strassburgo o interrogou sobre sua pregação; ele negava conexão com os anabatistas e qualquer defesa de afronta às autoridades, alegando ser apenas uma testemunha de Cristo; o sínodo, no entanto, considerou-o um revolucionário. Hoffman continuou preso com Klaus Frei; em 1539 o sínodo tentou tirá-lo, mas ele permaneceu até 1543 , quando faleceu.

\section{ANÁLISES E CONCLUSÕES}

$\mathrm{Na}$ Livônia, mais do que no Império ou qualquer outra região a adotar o Luteranismo, a reforma teve a possibilidade inicial de subverter as relações tradicionais de classe, e assumiu papel de luta contra a desigualdade. Iniciativas nesse sentido foram tomadas não apenas da parte de camponeses ou lideranças rurais, mas de nomes que estavam ligados ao corpo principal do movimento. Ainda que Hoffman tenha lutado por 
todos os seus anos na Livônia para ser reconhecido pelas instituições como pregador avalizado e, desta forma, nunca tenha transposto a posição de pregador leigo, é notório que muitas de suas ideias não tenham sido tão diversas das de Tegetmeyer; a diferença de aceitação entre os dois e, principalmente, do impacto de suas mensagens, esteve mais ligada à posição e reconhecimento oficiais, obtidos por Tegetmeyer mas não por Hoffman.

Também é notório que, apesar do impacto que a pregação de Hoffman e similares a ele, como o pregador Jonas, obtiveram na primeira década de pregação Luterana na Livônia, após 1533 a elite local de proprietários germânicos já havia se adaptado consideravelmente à nova situação religiosa, tendo a habilidade de manter seus privilégios e a estrutura de poder dirigida em seu favor. Simultaneamente a influência e popularidade de pregadores carismáticos como Tegetmeyer e Hoffman, seria sufocada com o reforço de uma estrutura eclesiástica mais burocrática e subordinada às autoridades seculares (Arbusow, 1921: 644s; 697s).

Essa situação é bem exemplificada na trajetória do Burgomestre Laurentz Lang que, ainda que tenha sido atacado e denunciado por Hoffman na ocasião da distribuição de posses da antiga igreja, menos de uma década após fora hábil o suficiente para defender uma posição anti-radical no Landtag e, usando o exemplo prévio de Hoffman, atacar posições que a ele se assemelhassem, como nos casos de Sasse e Jonas.

Em uma análise mais ampla, a expansão da Reforma Luterana no Norte da Europa deu-se por fatores e circunstâncias que extrapolam as ações de ordem estritamente religiosa ou iniciativas de proselitismo, mas que igualmente não podem ser reduzidas a apenas iniciativas de acúmulo de poder da parte de monarcas e nobres.

Diversos agentes, com igualmente diversos objetivos, incluindo hegemonia regional, independência econômica e mesmo fortalecimento do poder régio, foram instrumentais na criação de circunstâncias apropriadas para a mudança religiosa na quase que totalidade dos reinos e estados no norte europeu no século XVI.

O caso da reforma sueca é exemplar de uma circunstância na qual o monarca, no processo de independência local e de fortalecimento de sua monarca, propicia condições para a execução de reformas religiosas, condições essas que foram aproveitadas por indivíduos interessados na transformação espiritual de suas sociedades e que se valeram da égide real para tanto. 
Já o caso da Livônia foi sui generis por se dar em uma localidade organizada numa sistemática de poder distinta de outras regiões, não apenas no âmbito do Norte Europeu, mas da Europa, de forma geral. No caso em questão, a Confederação Livoniana dividia a terra entre propriedades administradas por organizações eclesiásticas, no caso diversos arcebispados e as Ordens Teutônicas, que enfrentavam oposição de governos secularizados das cidades majoritamente alemãs e ligadas à Liga Hanseática.

A população local, no entanto, não era formada de alemães, mas de povos nativos do báltico como letões, livônios e estonianos, tornando o tecido social mais complexo e aumentando o número de oposições e potenciais de conflito, que foram aproveitados, quiçá de forma inconsciente, pelos primeiros reformadores ali.

Há de se salientar as diferenças entre os dois casos e as possibilidades de aplicação de reforma religiosa em um âmbito mais notadamente popular na Livônia. A despeito das dificuldades enfrentadas por Hoffman em diversas cidades da Livônia, os componentes apocalípticos e populares de sua pregação não foi o único fator de oposição encontrado pelo mesmo da parte das autoridades locais, e possivelmente não foi o fator de maior peso em sua negação. Seu status de pregador leigo, não avalizado pelas instituições - fossem eclesiásticas ou seculares - teve peso muito maior em sua rejeição e eventual expulsão da região; a despeito das recomendações efetuadas por indivíduos estabelecidos como Lutero, Buggenhagen, Knopken e Tegetmeyer, Hoffman nunca transporia em definitivo seu status de pregador leigo enquanto na Livônia.

Como suporte a essa análise, apresentamos a trajetória de Sylvester Tegetmeyer, cuja pregação apresentou muitos pontos em questão com as mensagens de Hoffman; a amizade dentre os dois, ao menos no início de suas carreiras, é também elemento indicativo de, ao menos, certa confluência de ideias. Há de se salientar também que as fronteiras entre tendências sectárias e radicais, por um lado, e institucionais e "ortodoxas", por outro, dificilmente se aplicam aos dois reformadores referidos. Hoffman, em seu retorno de Wittenberg em 1525, seria muito claro em sua negação de revolução social e seu desejo de concórdia e convivência pacífica entre os diversos grupos sociais; nesse sentido, a pregação de Tegetmeyer, ao menos em sua fase inicial, foi tão ou mais disruptiva do que a de Hoffman. A diferença entre ambos foi a proveniência eclesiástica de Tegetmeyer, que propiciaria ao mesmo o escape em situações nas quais o destino de Hoffman não seria tão generoso. 


\section{REFERÊNCIAS BIBLIOGRÁFICAS}

ARBUSOW, Leonid. Die Einführung der Reformation in Liv-, Est- und Kurland. Leipzig: Scientai Verlag, 1921, reimpresso em 1964.

BÖTHFÜHR, Heinrich Julius. Tegetmeyer, Sylvester. In: Allgemeine Deutsche Biographie (ADB). Band 37. Leipzig: Duncker \& Humblot, 1894, p. 529.

DANIEL-ROPS. A Igreja da Renascença e da Reforma. I. A Reforma Protestante. São Paulo: Quadrante, 1996.

DEPPERMANN, Klaus. Melchior Hoffman: Social Unrest and Apocalyptic Visions in the Age of Reformation. London: T. \& T. Clark, 1987 [1979].

DRUVIN̦A, Ilze. No tulkotāja, notas sobre a tradução de PACKULL, Werner. Melhiors Hofmanis Livonijas Reformācijā: sektu veidošanās In: Cel̦š 1996 n48. Rīga: Latvijas Universitāte, pp. pp.24-26.

ESTEP, William. The Anabaptist Story. Grande Rapids, Michigan: William B. Eerdmans Publishing Company, 1975 [1963].

GRUDULIS, L. The Reformation and Public Education in the 16th and 17th Century Latvia, in: GOLZ, Reinhard \& MAYRHOFER (eds). Luther and Melanchthon in the Educational Thought of Central and Eastern Europe. Münster: Lit Verlag, 1998, pp. 128-133.

JOHANNESSON, Kurt. The Renaissance of the Goths in Sixteenth-Century Sweden: Johannes and Olaus Magnus as Politicians and Historians. Berkeley, Los Angeles \& Oxford: University of California Press, 1991[1982].

HAUSMANN, Richard. Knopken, Andreas. in: Allgemeine Deutsche Biographie, herausgegeben von der Historischen Kommission bei der Bayerischen Akademie der Wissenschaften, Band 16, 1882, pp.324s

LAANTEE, Karl. The Beginning of the Reformation in Estonia. In: Church History, Vol. 22, No. 4, 1953, pp.269-278.

MUTHER, Theodor. Abundi von Schwan, Johannes. In: Allgemeine Deutsche Biographie (ADB). Band 1. Leipzig: Duncker \& Humblot, 1875, p. 25.

OPSAHL, Erik. Water or Beer? Anti-German Sentiments in Scandinavia in the Late Middle Ages. The Case of Norway. In Bisgaard, Lars \& Pettitt, Tom (eds). Guilds, Towns, and Cultural Transmission in the North, 1300-1500, Odense: University Press of Southern Denmark, 2013. pp.73-90.

PACKULL, Werner. Melhiors Hofmanis Livonijas Reformācijā: sektu veidošanās. In: Cel̦š 1996 n48. Rīga: Latvijas Universitāte, pp.22-48. Tradução para o letão com notas e introdução de Melchior Hoffman's experience in the Livonian Reformation: the dynamics of sect formation. Werner O. Packull. 59:130-146 Ap 1985.

PACKULL, Werner. Sylvester Tegetmeier, father of the Livonian Reformation: A fragment of his diary, in Journal of Baltic Studies, 16:4, 1985, pp.343-56.

PETERSEN, Rodney. Preaching in the Last Days: The theme of 'Two witnesses in the sixteenth and seventeenth centuries'. New York \& Oxford: Oxford University Press, 1993. 
URBAN, William. The Teutonic Knights: a military history. London: Greenhill books, 2003.

WILLIAMS, George Hunston. The Radical Reformation, $3^{\text {rd }}$ edition. Missouri: Truman State University Press, 1992 [1962].

WOLKE, Lars Ericson. Stockholms Blodbad. Stockholm, 2006.

\section{FONTES PRIMÁRIAS}

Chytraeus, David. Davidis Chytraei chronicon Saxoniae et vicinarum aliqout gentium ab anno Christi 1500 usque ad M.D.XCIII. Lipsiae 1593.

Diário de Tegetmeyer. In: Arndt, Lieben Chronicle, Hall 1753, p. 190.

Recebido em: 10/10/2017

Aprovado em: 15/1/2018 